\title{
Fuel Cell 3D Contour Simulation of Serpentine Flow Field Inside Cubic Channels
}

\author{
Akeel M. Ali Morad ${ }^{1}$, Hala E. Obeed ${ }^{2}$, Fatima A. Khalaf ${ }^{3}$, Noor H. Jawad ${ }^{4}$, Zahraa K. \\ Jabar $^{5}$, Mariam A. Moustafa ${ }^{6}$ \\ \{akeel@stu.edu.iq ${ }^{1}$, zah78567@gmail.com ${ }^{2}$, jhussein907@gmail.com ${ }^{3}$ \} \\ Southern Technical University, Basra Eng. Technical College, fuel and energy eng. Deprt ${ }^{1}$ \\ Southern Technical University, Basra Eng. Technical College, fuel and energy eng. Deprt ${ }^{2,3,4,5,6}$
}

\begin{abstract}
In this study, we described the behavior of the serpentine flow field inside the fuel of a proton exchange membrane fuel cell (PEMFC). Pressure drop, inlet velocity, oxygen and gas diffusion layer (GDL), and current density determine the design of the fuel cell. The other parameters predicted in the open literature, such as temperature, humidity, etc., are not taken into account here. COMSOL Multiphysics 5.4 Software was used to simulate and test the electrochemical reactions governing equations. Three inlet velocities and three of $(1.5,2.5$, and $3.5 \mathrm{~m} / \mathrm{sec})$ cubic channels are used to show the effect of a turbulent flow without wall slip. By analyzing the results, it can be concluded that the serpentine flow field enhances the performance of fuel cells with cubic channel geometry. We found a good correlation between the current density and cell voltage at different inlet velocities.
\end{abstract}

Keywords: Serpentine Flow Field, 3D Contour Analysis, Fuel Cells, Cubic Channels.

\section{Introduction}

Fuel cells have recently attracted more researchers' attention. Applications in the industrial sector, due to global warming and fuel cost problems [1-5]. The last fifty years have seen many studies focused on compiling the use of water with another electrolyte to produce voltages and currents [6-9]. All these parameters played an important role in the design of the fuel cell membrane and the flow, whether single or two-phase [10-12]. The Serpentine flow is well known in the field of the fuel cell as a modern style of flow inside the channels. The designers developed new arts for the competitions of the fuel cell at serpentine flow. Recently published papers used the geometry of the channel as (M) [13]. In the catalyst layer and gas diffusion layer on the cathode side, they found a constant oxygen molar concentration. [14] uses a multiserpentine with slots and hybrid geometry. The best electrical performance was achieved with less pressure drop inside the geometry, and therefore, less noise was generated. Through a threedimensional wave flow channel, the channel geometry accelerates electrochemical reactions in the catalytic layer [15]. Their work results on the optimal flow channel are at minimum depth. The reaction inside the flow channel is observed more sensitive with relative humidity which showed by [16]. The experimental results shown at the increase in the humidity level, the performance of the cell increased.

In this study, we organized to preset the effect of the 3D serpentine flow field inside the three cubic channels of the fuel cell. The simulation is done used the free demo of the modern 
software COMSOL Multiphysics 5.4. Most of the effective parameters were shown and compared with opened pieces of literature.

\section{Problem Formation}

The design for fuel cells depends upon the type of fuel utilized, current density, mass of the oxygen diffused and reacts with (GDL), and the pressure drop in each channel of the cell. The modern way is approached to use serpentine flow field and predicted with three parallel of equal lengths channels to an aligned of reactant distributed at fluid over the electrode area to identical in resistance flow. Nevertheless, this design may induce some gratuitously in the high-pressure drops with low-temperature fuel cells, obstructing because some of the water will be condensed which occurred in the bends. This design for serpentine channel to function used the cross-flow through channel-to-channel, to plot the essential convection in the porous material layer, and moderated it instead of a large cross-flow due to lead stagnant zones. The modern way is approached to use serpentine flow field and predicted with three parallel of equal lengths channels to an aligned of reactant distributed at fluid over the electrode area to identical in resistance flow.

This design for the serpentine channel used the cross-flow through channel-to-channel, to plot the essential convection in the porous material layer, and moderated it instead of a large crossflow due to lead stagnant zones. The cathode is conditioned at the bottom of the GDL domain, while, the description of voltage used a lumped resistance, the anode, membrane, and GDL which arranged as shown in Fig 1. The design is consists of three inlets and three outlets cubic channels and the underlying is the GDL domain and faced the cathode at the bottom.

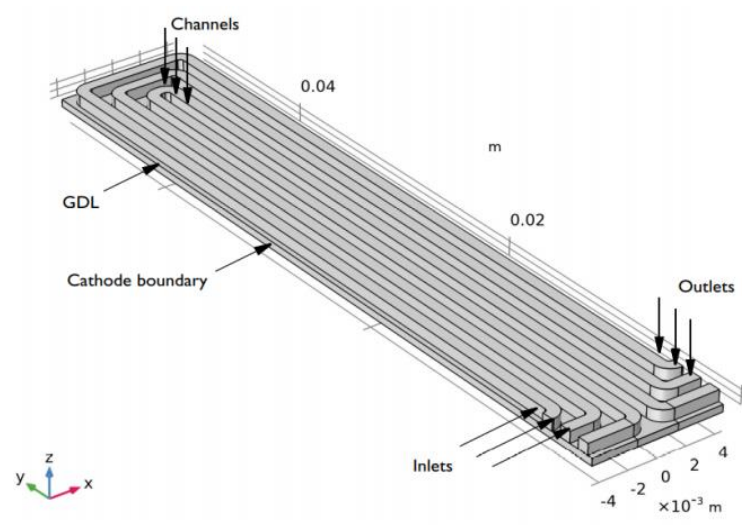

Fig 1. Model geometry.

Table 1. Shows all the input parameters to the simulated model.

\begin{tabular}{lc}
\hline Item & Expression \\
\hline Rib width & $0.7(\mathrm{~mm})$ \\
Channel width & $0.8(\mathrm{~mm})$ \\
\hline
\end{tabular}




\begin{tabular}{|c|c|}
\hline Plate width & $50(\mathrm{~mm})$ \\
\hline Channel height & $0.8(\mathrm{~mm})$ \\
\hline GDL height & $0.5(\mathrm{~mm})$ \\
\hline Channel-to-channel space & $1.5(\mathrm{~mm})$ \\
\hline Channels Number & 3 \\
\hline $\begin{array}{l}\text { Channel inner radius at } \\
\text { corners }\end{array}$ & $0.25(\mathrm{~mm})$ \\
\hline Cell Voltage (V) & 0.4 \\
\hline Open circuit voltage (V) & 1.23 \\
\hline $\begin{array}{l}\text { Lumped anode }+ \text { membrane } \\
\text { resistance }\end{array}$ & $0.285\left(\mathrm{ohm} * \mathrm{~cm}^{2}\right)$ \\
\hline Cell temperature (K) & $180+273.15$ \\
\hline GDL porosity & 0.4 \\
\hline $\begin{array}{l}\text { Inlet mass fraction of } \mathrm{H}_{2} \mathrm{O} \\
\text { (cathode) }\end{array}$ & 0.023 \\
\hline $\begin{array}{l}\text { Inlet mass fraction of } \\
\text { oxygen (cathode) }\end{array}$ & 0.228 \\
\hline
\end{tabular}

\subsection{Governing equations}

The reactions occurring in the cell are described by the following formulas of the porous cathode reaction according to[13]:

$$
\mathrm{O}_{2}+4 \mathrm{H}^{+}+4 e^{-} \leftrightarrow 2 \mathrm{H}_{2} \mathrm{O}
$$

Where, $\mathrm{O}_{2}$ is oxygen, $\mathrm{H}$ hydrogen, $\mathrm{H}_{2} \mathrm{O}$ is water.

The cumulative response in PEMFC fuel cell to calculate local current density, iloc which depend upon the oxygen concentrated according to the kinetic expression below[1]:

$i_{l o c}=i_{o}\left(\exp \left(\frac{\alpha_{a}}{R T} F \varphi_{C}\right)-\left(\frac{c_{O_{2}}}{c_{o_{2 . r e f}}}\right) \exp \left(-\frac{\alpha_{C}}{R T} F \varphi_{C}\right)\right)$

Where, $\mathrm{R}=$ universal gas constant, Temperature, $\alpha=$ transfer coefficient for cathode and anode, $\mathrm{F}=$ Faraday constant equal $\left(96487 \mathrm{C} \mathrm{mol}^{-1}\right), \varphi=$ cathode overpotential, Local oxygen concentration and the reference concentration of oxygen.

The combinations for both boundaries of the electrolyte-electrode Interface set up the mass flow boundaries according to the stoichiometric coefficient of the electrodes reactant. The flow is assumed without wall slip used for the wall of the channel, while the wall slip conditions are considered for the GDL walls.

The cathode potential $\varphi$, is calculated by relating the various parts of the cell according to:

$\varphi_{C}=\boldsymbol{E}_{\text {cell }}-\boldsymbol{E}_{O C V}-\boldsymbol{R}_{\text {iloc }}$ 
Where $E_{\text {cell }}$ is the cell potential, $E_{O C V}$ is the open circuit cell voltage and $R$ is the lumped resistance of membrane, anode, and the GDLs. the $3 \mathrm{D}$ flow of continuity equation is [1] :

$\frac{\partial(\rho u)}{\partial x}+\frac{\partial(\rho v)}{\partial y}+\frac{\partial(\rho w)}{\partial z}=-\frac{\partial \rho}{\partial t}$

Where, $\rho=$ density, $\mathrm{u}, \mathrm{v}, \mathrm{w}$ are the velocity components of the $\mathrm{x}, \mathrm{y}$, and $\mathrm{z}$ respectively.

In porous electrodes, the momentum equation can be written as:

$\nabla \cdot(\varepsilon \rho \underset{v}{\rightarrow} \vec{v})=-\varepsilon \nabla p+\nabla \varepsilon \tau+S m$

The momentum equation in the $\mathrm{x}$-direction is :

$$
\begin{array}{r}
u \frac{\partial(\rho u)}{\partial x}+v \frac{\partial(\rho u)}{\partial y}+\omega \frac{\partial(\rho u)}{\partial z}= \\
-\frac{\partial p}{\partial x}+\frac{\partial}{\partial x}\left(\frac{\mu \partial u}{\partial x}\right)+\frac{\partial}{\partial y}\left(\frac{\mu \partial u}{\partial y}\right)+\frac{\partial}{\partial z}\left(\frac{\mu \partial u}{\partial z}\right)+\operatorname{Sm}
\end{array}
$$

Where $S_{\mathrm{m}}$ is mass sink term. It can use the expression for $\mathrm{y}$ and $\mathrm{z}$-direction (just changed the composition of each direction).

Diffusion mass flux vectored can calculate from Fick's equation is :

$\overrightarrow{\mathrm{j}}_{\mathrm{i}}=\sum_{j=1}^{N-1} \rho \operatorname{Dij} \nabla \underset{\mathrm{yi}}{\rightarrow}$

Where Dij is the diffusivity of species.

The heat is transferred due to the chemical source, the Brinkman Equations is[17] :

$$
\begin{aligned}
& \frac{1}{\epsilon_{P}} \rho(u \cdot \nabla) u \frac{1}{\epsilon_{P}}=\nabla \cdot[-p I+K]-\left(\mu K^{-1}+\beta_{F}|u|+\frac{Q_{m}}{\epsilon_{P}^{2}}\right) u+F \\
& \nabla .(\rho u)=Q_{m}, K=\mu \frac{1}{\epsilon_{P}}\left(\nabla u+(\nabla u)^{T}-\frac{2}{3} \mu \frac{1}{\epsilon_{P}}(\nabla \cdot u) I\right.
\end{aligned}
$$

Where $\mathrm{k}$ is the conductivity of the polar plate. And for Transport of Concentrated Species is:

$$
\begin{aligned}
& \nabla . j_{i}+\rho(u . \nabla) \omega_{i}=R_{j} \\
& j_{i}=-\left(\rho D_{i}^{m} \nabla \omega_{i}+\rho \omega_{i} D_{i}^{m} \frac{\nabla M_{n}}{M_{n}}-j_{c, i}+D_{i}^{T} \frac{\nabla T}{T}\right. \\
& D_{i}^{m}=\frac{1-\omega_{i}}{\sum_{k \neq i} \frac{X k}{D_{i} k}}, \quad M_{n}=\left(\sum_{i} \frac{\omega_{i}}{M_{i}}\right)^{-1}
\end{aligned}
$$




\subsection{Physical Model}

To run the model, the proton exchange membrane fuel cell (PEMFC) was designed and tested successfully by COMSOL Multiphysics 5.4 software. Fig 2 shows the three inlet cubic channels with three cubic outflow channels. All dimensions and the operating parameters that were input to the run are shown in Table1. The model test with three different inlet velocities ranged as $(1.5,2.5$, and $3.5 \mathrm{~m} / \mathrm{sec})$. Table 2 shows the element quality of the fuel cell domain. Fig 3 and Fig 4 show the mesh of the whole fuel cell and the test of the mesh.

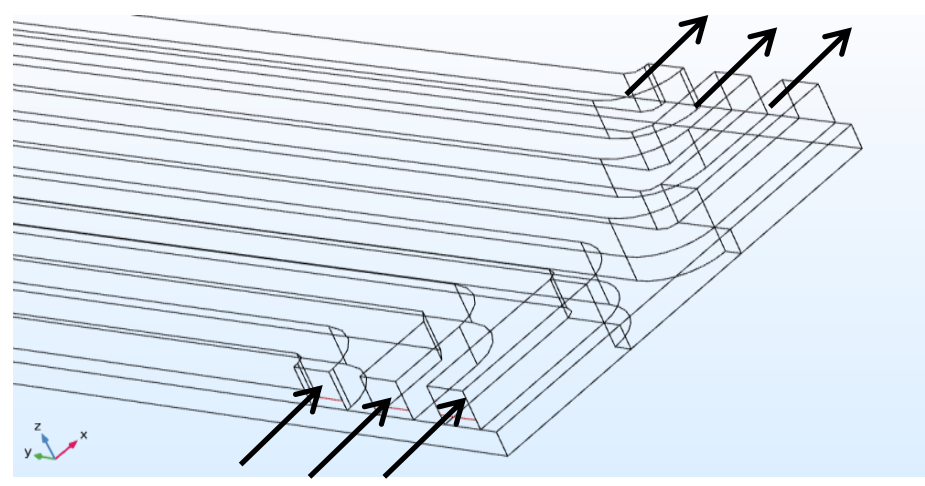

Fig 2. Dimensions of simulated.

Table 2. Statistical of element quality.

\begin{tabular}{cc}
\hline Description & Value \\
\hline Min. element quality & 0.08319 \\
Average element quality & 0.673 \\
Tetrahedron & 83113 \\
Triangle & 46997 \\
Edge element & 5041 \\
Vertex element & 140 \\
Nu. of elements & 251489 \\
Element volume ratio & 0.01344 \\
\hline
\end{tabular}

Mesh

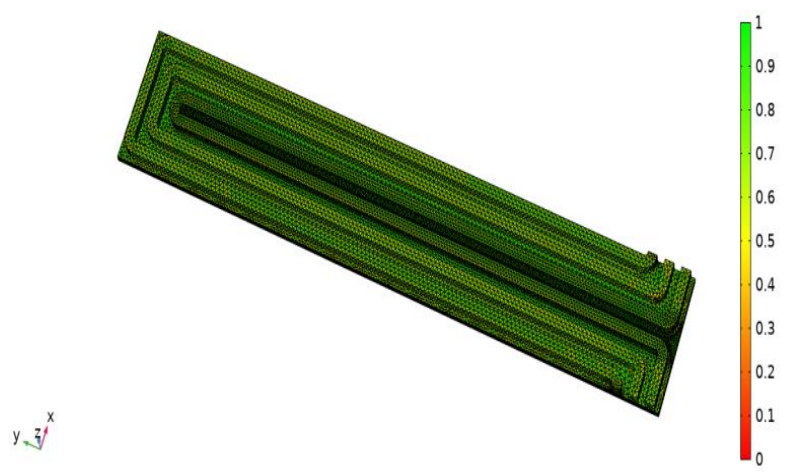

Fig 3. 3D mesh domain test. 


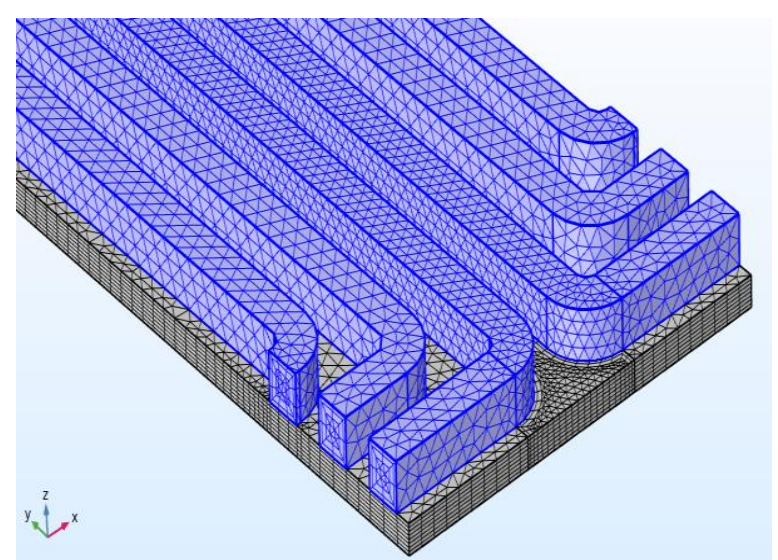

Fig 4. 3D snapshot for inlet and outlet meshing domain test.

\section{Results and Discussions}

\subsection{Model Validation}

Fig 5, explained the comparison of present work with previous work which was obtained from the experiment data's [1]. Their data compared at the ranged of the current density approximately from ( 0.22 to $\left.1.07 \mathrm{~A} / \mathrm{cm}^{2}\right)$. Our results are simulated at the inlet velocity of (1.5 $\mathrm{m} / \mathrm{sec}$ ). The Figure illustrates the current is slight decreases with varying cell voltage. While for previous work, the clear slop of line increased the current density vs cell voltage.

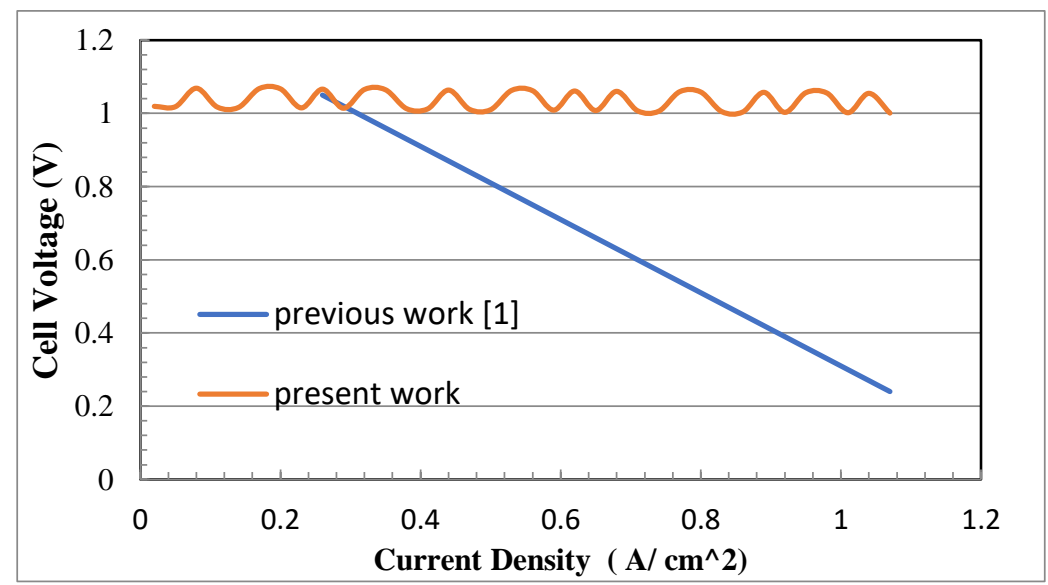

Fig 5. The comparison between present work with [1].

\subsection{Oxygen distribution}

Fig 6 shows the oxygen distribution in the fuel cell channels in 3D. Oxygen concentration is higher at the inlet of each channel, and then gradually decreases towards the outlet. With opened pieces of literature, the reduction in oxygen concentration leads to a slower reaction rate of the cell. In the channels, the oxygen mass fraction is significantly higher. As inlet velocity increases, 
the high concentration value of oxygen starvation is remarkably reduced at the cell's outlet. In Figure 6 , the oxygen distribution is shown at an inlet velocity of $(1.5 \mathrm{~m} / \mathrm{sec})$ while Figs $6-\mathrm{b}$ and $6-\mathrm{c}$ show inlet velocities of 2.5 and $3.5 \mathrm{~m} / \mathrm{sec}$.

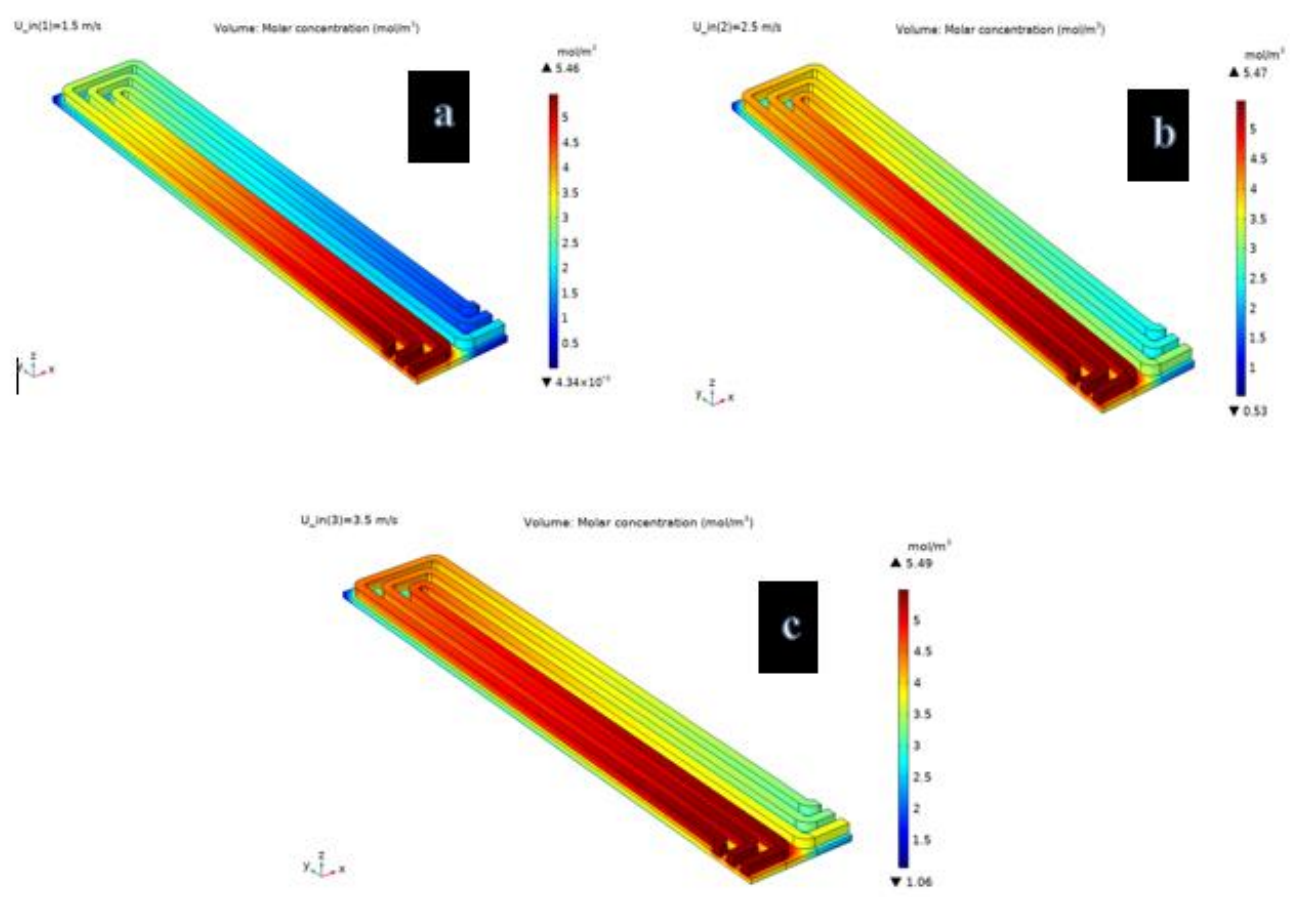

Fig 6. Distribution of oxygen concentration.

\subsection{Velocity Distribution}

Fig 7 shows the 3D velocity distribution of the water inside the fuel cell channels. Each cell of the channel displays a serpentine flow field. The distribution inside the channel changed as velocity increased at the inlet. The more reaction between gas and diffusion layer, the more reliable the reaction. In addition to the velocity distribution, the pressure distribution can also be used to show the behavior inside the fuel channel. As inlet velocity increases, the pressure increases and gradually decreases until it reaches a lower value at the outlet as shown in Fig 8. 


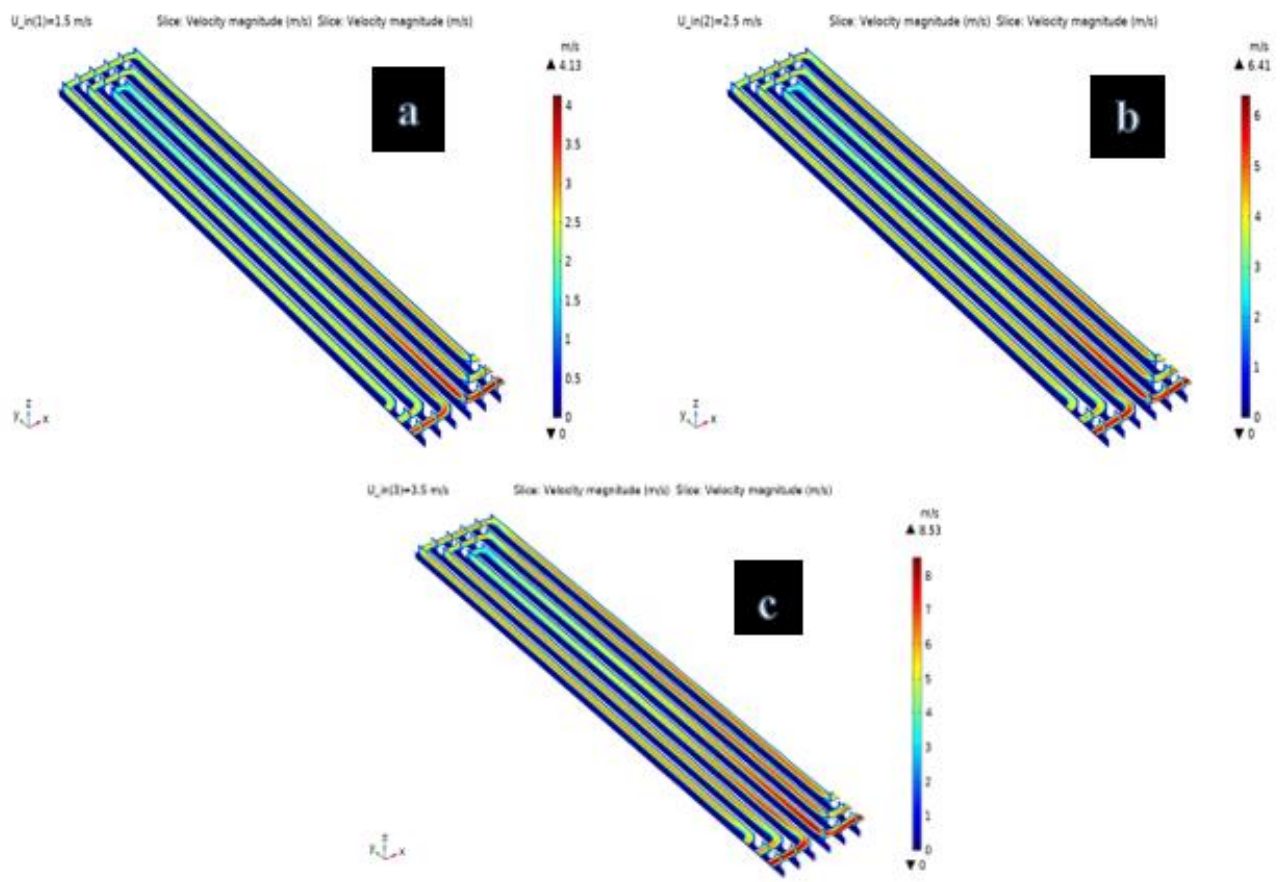

Fig 7. 3D velocity distribution at three inlet velocities.

\subsection{Current Density}

Fig 9 illustrates the current density distribution at the cathode base. The most uniform distribution of current density is seen at serpentine flow fields, as is the distribution of oxygen molar concentration. Gas diffusive layers in the cathode release more reactants and can participate in the electrochemical reaction of the catalyst layer, as shown in Fig 10. These results can be used to improve and implement serpentine flows in fuel cell PEMFCs. 


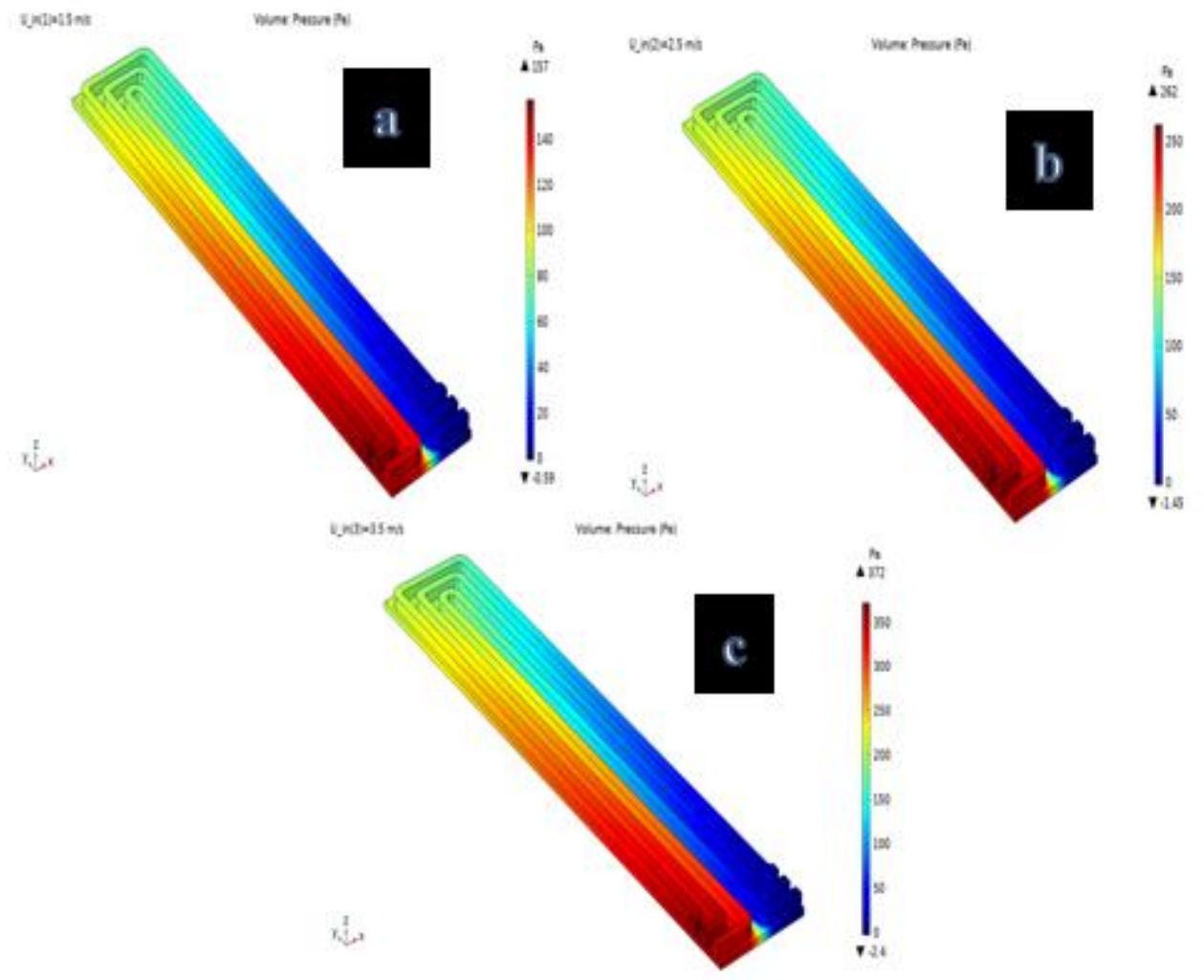

Figure 8. 3D pressure drop distribution at three inlet velocities.

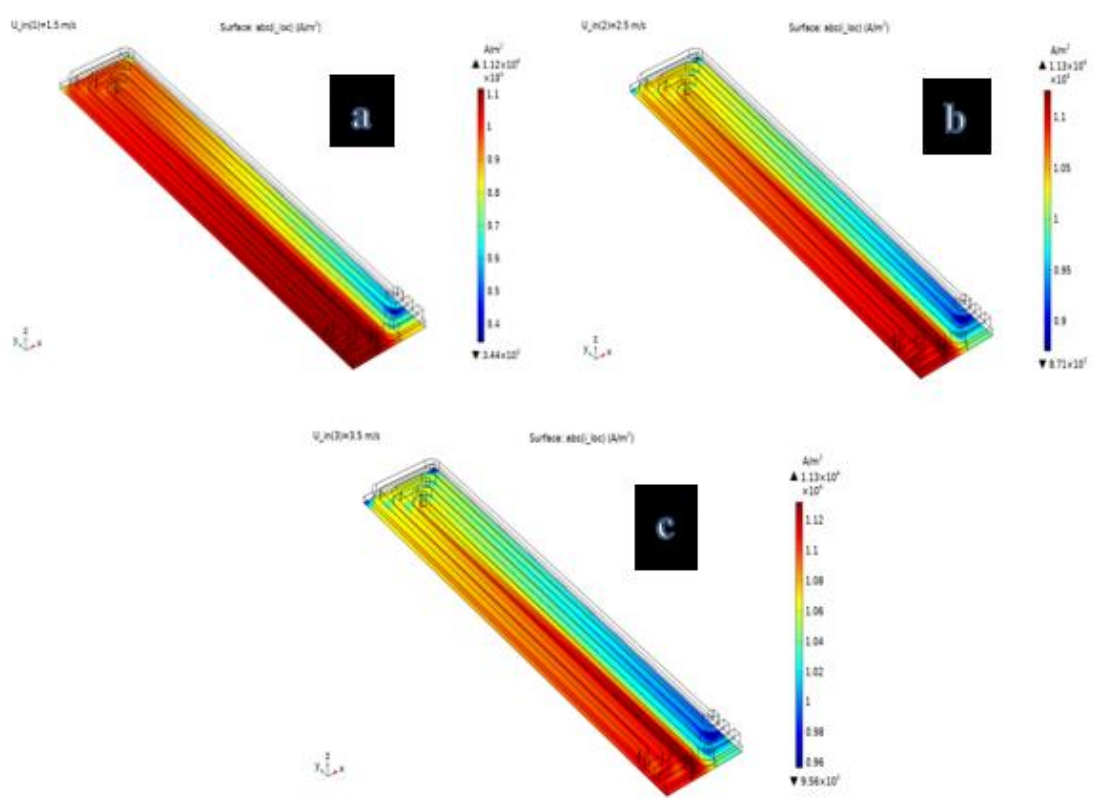

Fig 9. 3D current density distribution at the cathode at three inlet velocities. 

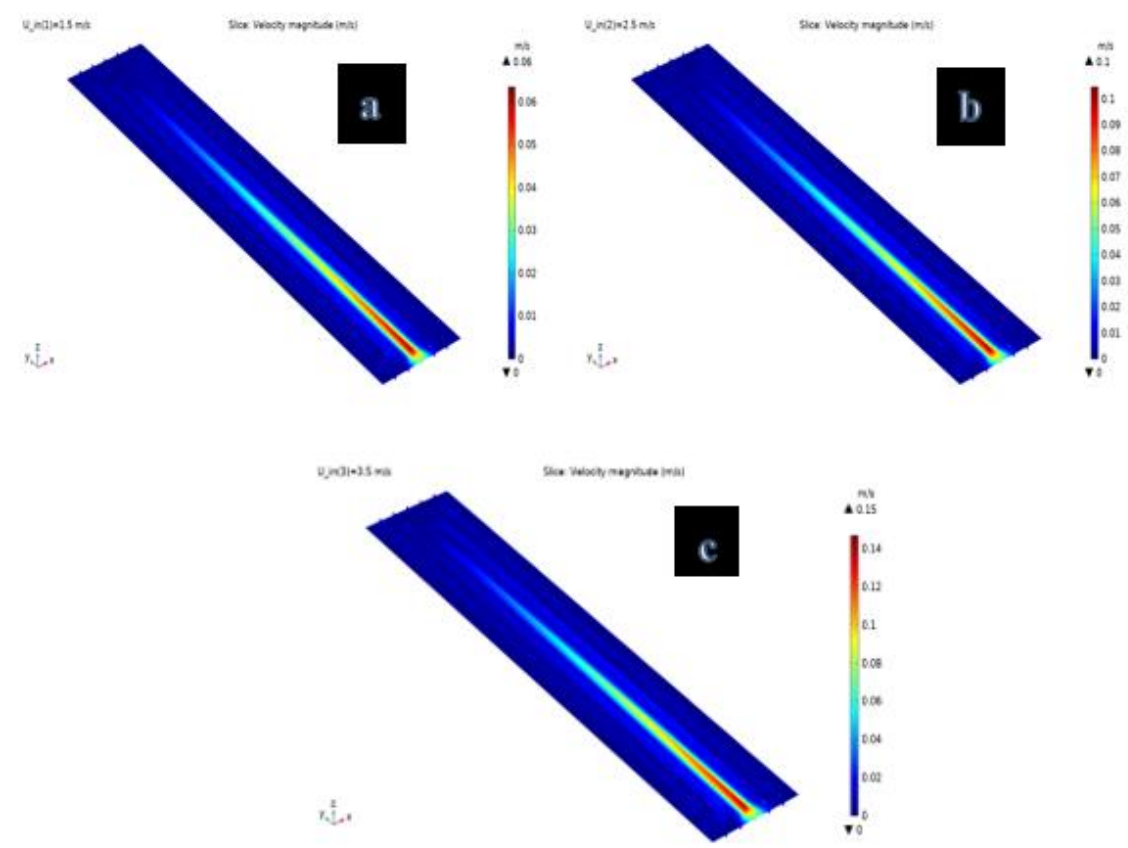

Fig 10. 3D gas diffusion layer (GDL) distribution at the cathode at three inlet velocities.

\section{Conclusion}

Three different inlet velocities were used to model the serpentine flow field in 3D. We use three cubic channels with inlet and outlet dimensions of $(0.8 * 0.8 \mathrm{~mm}$ with average plate width of $50 \mathrm{~mm}$ ), all other parameters are listed in Table 1. By using the COMSOL Multiphasic 5.4 software (Free Demo), the model of the simulation is successfully run to test the effects of varying the inlet velocity on the performance of the fuel cell. The following conclusion follows:

1. The higher performance to produce the current density with serpentine flow field arrangement is obtained in the present work and so for observed by the former researchers.

2. 3D oxygen distribution uniformly at higher values inlet and gradually reduction it to outlet due to decreases the mass fraction when it reacts with GDL.

3. 3D current density distributed at the cathode is observed that the most uniform at serpentine flow field. The gas diffusive layer in the cathode is more reactant given participated the catalyst interchanged.

4. The increases in inlet velocities that lead to high-pressure drop values were observed through the inlet and outlet of each channel.

\section{References}

[1] Fatemeh Hashemi, Soosan Rowshanzamir, Mashallah Rezakazemi. CFD simulation of PEM fuel cell performance: Effect of straight and serpentine flow fields. (2012). Mathematical and Computer Modelling.Volume 55, Issues 3-4, Pages 1540-1557. 
[2] Li X, Sabir I. Review of bipolar plates in PEM fuel cells: flowfield designs. Int J Hydrogen Energy 2005;30:359e71.

[3] Nik Suhaimi Mat Hassan, Wan Ramli Wan Daud, Kamaruzzaman Sopian, Jaafar Sahari. Water management in a single cell proton exchange membrane fuel cells with a serpentine flow field. (2009). Journal of Power Sources 193. 249-257.

[4] B. Rismanchi, M.H. Akbari, Performance prediction of proton exchange membrane fuel cells using a three-dimensional model. (2008). International Journal of Hydrogen Energy 33 439-448.

[5] Fan L, Zhang G, Jiao K. Characteristics of PEMFC operating at high current density with low external humidification(2017). Energy Convers Manage;150:763-74.

[6] A. Alaswad, A. Baroutaji b, H. Achour, J. Carton, Ahmed Al Makky, A.G. Olabi. Developments in fuel cell technologies in the transport sector. (2016). International Journal of Hydrogen Energy

Volume 41, Issue 37, 5, Pages 16499-16508.

[7] Zhongying Shi, Xia Wang. A numerical study of flow crossover between adjacent flow channels in a proton exchange membrane fuel cell with serpentine flow field. (2008). Journal of Power Sources .185, 985-992.

[8] Lin L, Zhang X X, Feng H T, et al. Optimization of a serpentine flow field with variable channel heights and widths for PEM fuel cells. (2010). Sci China Tech Sci, 53: 453-460, DOI: 10.1007/s11431010-0009-4.

[9] P.V. Suresh, S. Jayanti, A.P. Deshpande, P. Haridoss. An improved serpentine flow field with enhanced cross-flow for fuel cell applications. (2011). International Journal of Hydrogen EnergyVolume 36, Issue 10, Pages 6067-6072.

[10] Morad, A. M. A. A Two-Phase Pressure Drop Model for Homogenous Separated Flow for Circular Tube Condenser, Examined with Four Modern Refrigerants. (2018). Journal of Advanced Research in Fluid Mechanics and Thermal Sciences, 52 (2), 274-287.

[11] Andrew Higier, Hongtan Liu. Direct measurement of current density under the land and channel in a PEM fuel cell with serpentine flow fields. (2009). Journal of Power Sources 193 (2009) 639-648.

[12] Kush Chadha, Serguei Martemianov, Anthony Thoma. Study of new flow field geometries to enhance water redistribution and pressure head losses reduction within PEM fuel cell. (2021). International Journal of Hydrogen Energy Volume 46, Issue 10, 8, Pages 7489-7501.

[13] Chen Yang, Zhongmin Wan, Xi Chen, Xiangzhong Kong, Jing Zhang, Taiming Huang, Xiaodong Wang. Geometry optimization of a novel M-like flow field in a proton exchange membrane fuel cell(2021). Energy Conversion and Management Volume 228, 15, 113651.

[14] Xi Chen, Zhengkun Yu, Chen Yang, Yao Chen , Chao Jin, Yuejiao Ding, Wenbin Li, Zhongmin Wan. Performance investigation on a novel 3D wave flows channel design for PEMFC. (2021). International Journal of Hydrogen Energy Volume 46, Issue 19, 16, Pages 11127-11139.

[15] Mehrdad Ghasabehi , Moosa Ashrafi , Mehrzad Shams. Performance analysis of an innovative parallel flow field design of proton exchange membrane fuel cells using multiphysics simulation. (2021). FuelVolume 285, 1 February 2021, 119194

[16] Aezid-Ul-Hassan Najmi, Ikechukwu S. Anyanwu, Xu Xie, Zhi Liu, Kui Jiao. Experimental investigation and optimization of proton exchange membrane fuel cells using different flow fields. (2021). Energy Volume 217, 15, 119313.

[17] R.Byron Bird, Warren E. Stewart, Edwin N. Lightfoat. Transport Phenomena. 2nd Edition, (2002). Wiley International Edition. 